\title{
Nanotheranostics and Coronavirus 2 (SARS-CoV-2)
}

\author{
Rajiv Kumar* \\ NIET, National Institute of Medical Science, India \\ *Corresponding author: Rajiv Kumar, NIET, National Institute of Medical Science, India
}

\begin{tabular}{|c|c|}
\hline ARTICLE INFO & ABSTRACT \\
\hline Received: July 26, 2021 & Citation: Rajiv Kumar. Nanotheranostics and Coronavirus 2 (SARS-CoV-2). Biomed J Sci \\
\hline Published: 絊 August 03, 2021 & \& Tech Res 37(5)-2021. BJSTR. MS.ID.006050. \\
\hline
\end{tabular}

\section{Opinion}

The severe acute respiratory syndrome coronavirus 2 (SARSCoV-2) causes the current outburst worldwide. Emergence of SARS-CoV-2 has affected a large population and has been identified as a serious threat to humans. To date, nanotechnology-based tools and devices consist of nanoparticles that revealed great potential for the prevention, diagnosis, and therapy of SARS-CoV-2 infection. Nanotechnology-based strategies are very efficient for rapid diagnosis [1]. Various other advanced nanomaterials are also considered for designing antiviral nanotechnology-based remedies, which can be considered a better source to deal with the problems associated with SARS-CoV-2, and the development of advanced tools, can be applied for rapid, accurate, and sensitive diagnosis [2]. These tools and devices can perform as effective disinfectants by delivering nanotherapeutics and antiviral agents into human cells. Cutting-edge tools, especially those, which is innovated by nanotechnology, can easily tackle SARS-CoV-2 infection. Novel strategies were designed for effective diagnosis of SARS-CoV-2 with the aid of nanotechnology and by employing various forms of nanoparticles. Currently, simultaneous efforts are discovering efficient drug remedies to treat viral infections and diseases. Nanotechnology-driven tools and devices are very effective in the management of SARS-CoV-2 pandemic and playing a key role in the development of newer nanotherapeutics [3].

Especially, nanosensors have already proven their value in the diagnosis of viral diseases. Multifunctional nanomaterials, quantum dots, and their various forms (liposomes, polymeric, lipid, metallic, and micelles) are very efficient in prevention, diagnosis, vaccination, and drug encapsulation [4]. These novel strategies can be expedited in the upgrading of pharmacological impact to treat
SARS-CoV-2 [5]. The antiviral efficiency of aforesaid nanotools and devices target the entering, expansions, binding, repetition, and budding of SARS-CoV-2 [6]. The antiviral effectiveness of inorganic nanoparticles should be further inspected and improved [7]. Here, the author points out the gap of knowledge that be existent in the managing of SARS-CoV-2 pandemic and expose the route of its unembellished impact on the respiratory system [8]. In the absence of the actual diagnostics and novel therapies, it is an unclear task to deal with SARS-CoV-2. As, such types of viruses spreads via humanto-human. In host cells, SARS-CoV-2 spread via symptomatic carriers and initiate damages in the organs [9].

To overcome these obstacles, the author projects the applications and uses of nanotechnology to present it overall as the birthplace of pharmacological agents and novel nanotherapeutic with the size of 10 to $200 \mathrm{~nm}$ scale. 3 These recommended remedies are site-specific and able to deliver nanotherapeutics to diagnose and eradicate the SARS-CoV-2. Even though these nanotools and devices can expand the human immune system specifically as required for ending the outbreak and infection stage of SARS-CoV-2 [10]. Nanotools and devices developed via nanotechnologies can be applied for mimicking the behavior of viruses for altering their harmful features and characteristics. For the same grounds, various efforts have been made for designing virus-like nanoparticles that can be applied for the preparation of nanodrugs for delivery and gene editing. Nanotherapeutics (nanocarriers or polymeric nanoparticles) can deal with mRNA and govern the initiation of the process of antigens making. These nanotools and devices can easily stimulate the immune system to fight SARS-CoV-2 [11].

Thus, these nanotherapeutics can perform as immunestimulating boosters and effectively generate a stronger immune 
response to cope with the negative impact of viral infection. Discussed nanomedicine formulation and synthesized nanodrugs can target the immune cells in the lungs in different medical conditions [12]. To fight these viruses, antibodies and antigens are essential, and a need is always there to craft them. The antibodies are recognized as small proteins, which can abolish invaders by hunting. For a perfect diagnosis, antibody tests can be accomplished by smearing the nanotechnology strategies. For example, gold nanoparticles can easily identify antibodies that are present in the blood and confirm SARS-CoV-2 infection.

\section{Acknowledgments}

Author (Rajiv Kumar) gratefully acknowledges his younger brother Bitto for motivation.

\section{References}

1. Bonam SR, Kotla NG, Bohara RA, Rochev Y, Webster TJ, et al. (2021) Potential immuno-nanomedicine strategies to fight COVID-19 like pulmonary infections. Nano Today 36.

2. Quirch M, Lee J, Rehman S (2020) Hazards of the cytokine storm and cytokine-targeted therapy in patients with COVID-19: Review. J Med Internet Res 22(8): e20193.

3. Weiss C, Carriere M, Fusco L, Capua I, Regla Nava JA, et al. (2020) Toward Nanotechnology-Enabled Approaches against the COVID-19 Pandemic. ACS Nano 14(6): 6383-6406.

\section{ISSN: 2574-1241}

DOI: $10.26717 /$ BJSTR.2021.37.006050

Rajiv Kumar. Biomed J Sci \& Tech Res

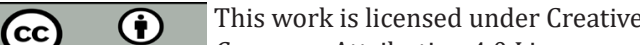
Commons Attribution 4.0 License

Submission Link: https://biomedres.us/submit-manuscript.php
4. Kumar R, Sharma M (2018) Herbal nanomedicine interactions to enhance pharmacokinetics, pharmaco- dynamics, and therapeutic index for better bioavailability and biocompatibility of herbal formulations. Journal of Materials Nano Science 5(1): 35-58.

5. Zhang JW, Hu X, Jin PF (2020) Cytokine Storm Induced by SARS-CoV-2 and the Drug Therapy. Chinese Pharm J 55: 333-336.

6. Nasrollahzadeh M, Sajjadi M, Soufi GJ, Iravani S, Varma RS (2020) Nanomaterials and nanotechnology-associated innovations against viral infections with a focus on coronaviruses. Nanomaterial 10(6): 1072

7. Pandey A, Nikam AN, Mutalik SP, Fernandes G, Shreya AB, et al. (2021) Architectured Therapeutic and Diagnostic Nanoplatforms for Combating SARS-CoV-2: Role of Inorganic, Organic, and Radioactive Materials. ACS Biomater Sci Eng 7(1): 31-54.

8. Khorsandi K, Fekrazad S, Vahdatinia F, Farmany A, Fekrazad R (2020) Nano Antiviral Photodynamic Therapy: a Probable Biophysicochemical Management Modality in SARS-CoV-2. Expert Opin Drug Deliv 18(2): 265-272.

9. Vazquez Munoz R, Lopez Ribot J (2020) Nanotechnology as an Alternative to Reduce the Spread of COVID-19. Challenges 11(2): 1-14.

10. Naji HS (2020) Cytokine Storm of SARS-CoV-2, the Virus that Causes COVID-19. Eur J Med Heal Sci 2(3): 245.

11. Thepmankorn P, Bach J, Lasfar A, Zhao X, Souayah S, et al. (2021) Cytokine storm induced by SARS-CoV-2 infection: The spectrum of its neurological manifestations. Cytokine 138: 155404.

12. Wang Y, Wang F, Geng J (2020) Cytokine and cytokine storm after SARSCoV-2 infection. Open Access Online-First Publ Res Pap COVID-19 pp. $1-7$.

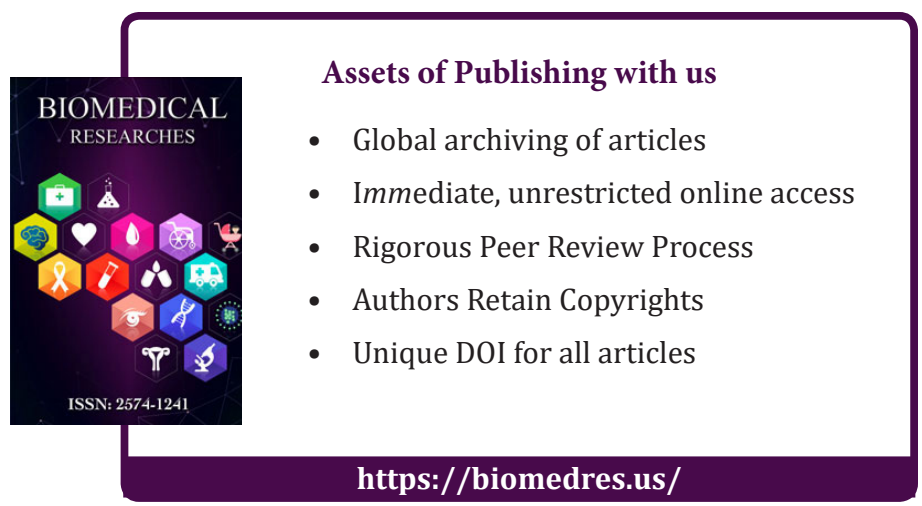

